\title{
Correction to: Experiences of pathways to mental health services for young people and their carers: a qualitative meta-synthesis review
}

\author{
Kathleen MacDonald ${ }^{1,2,3,4}$ (1) Manuela Ferrari ${ }^{1,2,3,4} \cdot$ Nina Fainman-Adelman ${ }^{1,2} \cdot$ Srividya N. Iyer $^{1,2,3,4}$
}

Published online: 24 December 2020

c) Springer-Verlag GmbH Germany, part of Springer Nature 2020

\section{Correction to:}

\section{Social Psychiatry and Psychiatric Epidemiology}

https://doi.org/10.1007/s00127-020-01976-9

The original version of this article contained an error in Fig. 1. A previous version of this figure was mistakenly used.

The original article can be found online at https://doi.org/10.1007/ s00127-020-01976-9.

Kathleen MacDonald

kathleen.macdonald@douglas.mcgill.ca

Srividya N. Iyer

srividya.iyer@mcgill.ca

1 Department of Psychiatry, McGill University, Montreal,

Canada

2 Douglas Research Centre, Montreal, Canada

3 ACCESS Open Minds, Pan-Canadian Youth Mental Health Services Research Network, Montreal, Canada

4 Prevention and Early Intervention Program for Psychosis (PEPP), Montreal, Canada 
Below is the correct figure.

Search update April 2020

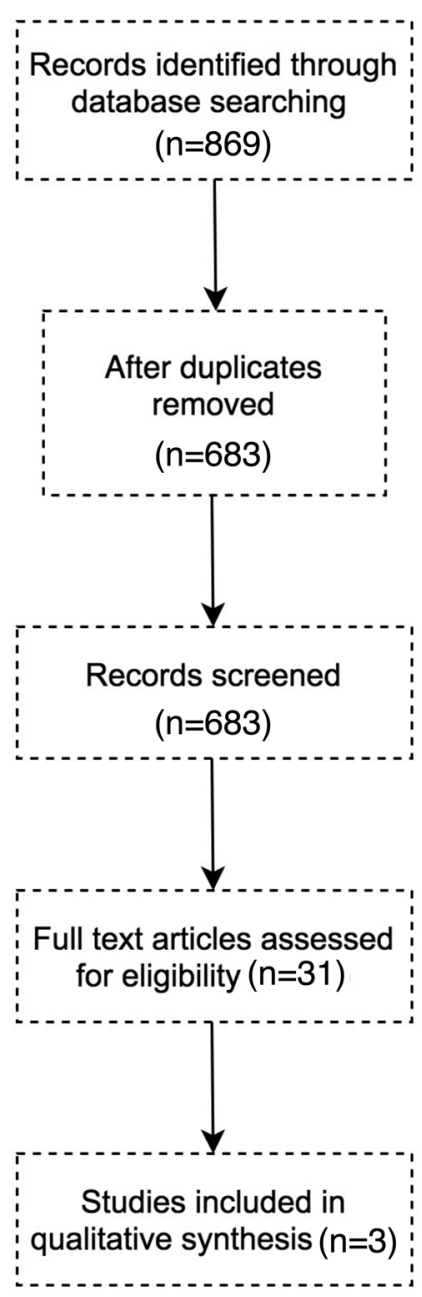

Additional records identified though other sources, including hand search of the journals

Qualitative Health Research, Journal of Adolescent and Child Health, as well as forward and backward citations mapping $(n=17)$

\section{database searching} $(n=17,381)$

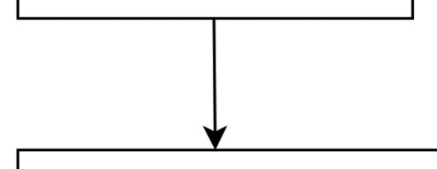

Records after duplicates removed $(n=11,398)$

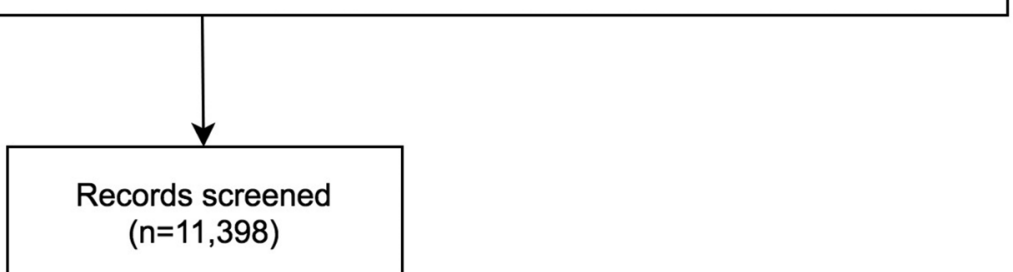

Full-text articles excluded $(n=837)$

Study objectives not related to review $=448$

Full text articles assessed for eligibility $(n=865$ )

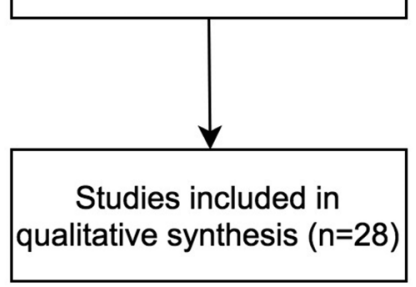

Study design (incl. quantitative, conference abstract, literature reviews, dissertations, etc) $=236$ Language $=85$ Age range $=69$

Total studies included in qualitative synthesis $(n=31)$

The original article has been corrected. 